\title{
LA ESCUCHA ETNOGRÁFICA EN \\ LA VIOLENCIA DE GÉNERO DESDE ESPACIOS EDUCATIVOS CULTURALES. REFLEXIÓN PARA DESCOLONIZAR EL FEMINISMO
}

\author{
PRÁXEDES MuÑoz SÁNCHEZ \\ MERCEdes ÁlVAREz García \\ Universidad Católica de Murcia
}

Recibido 2-05-215

Aceptado 23-05-2015

\section{Resumen}

Para tratar la violencia de género en espacios educativos, formales y no formales, se requiere de estrategias que identifiquen violencias y sus símbolos, para acercarnos a una visión antropológica más acorde con convergencias culturales y sociales. Se rechaza una única caracterización de la violencia que visibilice diversos comportamientos y dé relación a un reconocimiento público independiente de una integridad de lo privado y lo público, de la casa y de la comunidad. Se acentúa la complejidad de los símbolos que existen en múltiples sociedades, en este caso se verán experiencias que se han trabajado a partir de una etnografía reflexiva en espacios multiculturales e interculturales que constatan una necesidad de incorporar un entendimiento descolonizador de la violencia de género.

Palabras clave: violencia, género, feminismo, descolonización, espacios educativos, comunidad, etnografía.

\begin{abstract}
To deal with gender violence in formal and informal educational facilities, strategies are required to identify violences and their symbols, to be close to a more anthropological view agreeing with cultural and social convergences. A unique characterization of the violence that makes visible different behaviors and gives conexion with an independent public recognition of private and public, household and community
\end{abstract}


integrity is rejected. The complexity of the symbols that exist in many companies is accentuated, in this case experiences that have worked from a reflexive ethnography in multicultural and intercultural spaces confirm a need to incorporate a decolonization understanding of gender violence.

Key-words: violence, gender, feminism, decolonization, education spaces, community, ethnography. 


\section{Introducción}

A partir de un enfoque experiencial en diversos espacios educativos, destacamos significados y símbolos sobre la violencia de género a partir de reflexiones sobre qué es importante y cómo pueden resolverse los conflictos a favor de procesos descolonizadores de saberes sobre feminismos, que enmarcamos, como describe María Lugones ${ }^{1}$, en la intersección de raza, clase, género y sexualidad.

El objetivo es visibilizar la violencia de género desde la dimensión global que la diversidad cultural requiere. Consideramos la necesidad de apoyar una descolonización sobre cómo se entiende la violencia desde múltiples concepciones hegemónicas: feministas, académicas y expertos en intervención social, así como otras de prácticas colonialistas y creencias patriarcales.

En este caso desde la experiencia de colaboración y cooperación que se potencia en un diálogo de saberes ${ }^{2}$ intercultural e inclusivo de identidades en la alteridad, la investigación acción participante desde la etnografía, nos implica en visibilizar estas múltiples realidades donde los colaboradores, de diversa edad y cultura, conforman un saber democrático ${ }^{3}$. Dirigir nuestra mirada a enmarcar la violencia de género, aunque sea para identificarla, puede llevar consigo caracterizaciones que dejan de lado la alteridad, y fomente una colonización desde el feminismo occidental.

Para ello hay que reconocer como investigadoras nuestra propia formación y experiencias vividas, en este caso desde la pedagogía y la antropología, junto al activismo realizado por las personas participantes y sus vivencias,

1. LUGONES, María: «Colonialidad y Género: Hacia un feminismo descolonial», en Walter Mignolo (comp.). Género y Descolonialidad. Buenos Aires, Del Signo, 2008, p. 13.

2. DIETZ, Gunther. «Reflexividad y diálogo en etnografía colaborativa: el acompañamiento etnográfico de una institución educativa intercultural mexicana». Revista de Antropología Social 21(2012), pp.63-91.

3. MuÑOZ, Práxedes: «Experiencias de construcción de resistencias e identidades de género en colectivos de mujeres en Tabasco. Dilemas de la antropología comprometida. ¿Cambios posibles?». En Luis Rodríguez, Sergio E. Hernández y María del Carmen Ventura (coords.), Democracia, cultura política y ciudadanía en el México de hoy. México, UNAM, 2014, pp. 175-197. 
individuales y comunitarias, así como desde el diálogo de saberes de sus participantes en la etnografía que presentamos, relatamos sobre la temática de violencia de género. Además del cuestionamiento de nuestros propios saberes, que como mujeres y educadoras y educandas entre mujeres, podemos mostrar.

O como denomina Roberto DaMatta ${ }^{4}$ : la casa domina la calle», al referirse al espacio tan diferente cuando la lucha por la vida es un encuentro que puede ser difícil en el ámbito público, y más en cuanto a la violencia de género y el propio pensamiento de las niñas y niños en sus espacios íntimos. Pero es posible encontrar lo inverso, niñas que públicamente pueden estar integradas y requieran de «un hibridismo institucional $»^{5}$, y que se amparan cuando exista un debilitamiento del espacio íntimo o de «la casa». Ambos son espacios complejos, cargados de simbolismos que consideramos necesario visibilizar.

Apostamos por trabajar la violencia desde un proyecto como el Relaciona ${ }^{6}$, donde se valora la experiencia y el saber de quienes están en relación, y no confía solo en transmitir conocimientos sino en generar saberes desde la hetereogeneidad.

En resumen, se presenta una escucha activa de qué violencia hay, cómo se percibe la diferencia sexual, qué buenas prácticas se hacen y cómo deberían abordarse según los y las protagonistas de estos escenarios educativos, sus identidades, sus obstáculos y algunas iniciativas junto a sus propios saberes que convergen en relación.

\section{Descolonizar en el escenario educativo la violencia de género}

A partir de considerar que nuestro ámbito puede estar rodeado de relaciones e identidades colonizadoras, en conceptos como el feminismo, la masculinidad /desmasculinidad y la violencia de género, es una responsabilidad del educador y las instituciones analizar qué es real y qué es dirigido en función de intereses históricos o de un desconocimiento de la realidad cultural existente: cultura entre géneros, categorías rígidas de la división entre hombre y mujer, las construcciones del «binarismo de género», la violencia, la no-violencia, las relaciones afectivas dentro de códigos culturales o religiosos, entre otras.

No es reinventar la historia ni quedarnos en reflexiones no más, o en dar mil y una vuelta a posibilidades sociales, sino a observar e identificar

4. Da MatTa, Roberto. Carnavales, malandros y héroes. México, Fondo de Cultura Económica, 2002, pp. 245-247.

5. DA MATTA, Roberto. Op. cit.

6. SERRATO, Gloria Isabel; CERviÑo, M. ${ }^{a}$ Jesús y HERnÁNDEZ Graciela. «Formación en Relación». Cuadernos de Educación no sexista 24 (2008), pp. 19-30. 
urgencias para actuar más acorde a la realidad. Es necesario actualizar la movilidad y variabilidad de sucesos socioeducativos que se producen (migración, pobreza, exclusión, desarraigo, educación anti-emocional, des-comunicación, ¿desarrollo comunitario?, asimilación, etc.), lo que requiere de conocer cada escenario y a sus protagonistas de forma integral.

Hablar de violencia de género también puede ser en parte una colonización desde estructuras que crearon este concepto. La mayoría de veces se reconoce como «casi siempre violencia masculina» ${ }^{7}$. En el caso de la autora Milagros Rivera ${ }^{8}$, interpretamos su aportación en cuanto a que la violencia de género es la lucha de poder entre los sexos, pero a la vez explica «que el género está separado de la corporeidad $»^{9}$. Carlos Lomas ${ }^{10}$ admite una responsabilidad tenaz en el contexto sociocultural de cada persona, que delibera en «conflictos y desajustes» hacia ecos violentos que contribuye a pervivir el sexismo.

Con estos razonamientos destacamos la necesidad de deslegitimizar la clasificación de violencia, las subjetividades marcadas como verdades, las suposiciones y arquetipos e incluso las respuestas y silencios recibidos desde nuestro acompañamiento en la etnografía.

Para entender estas diferencias de género nos apoyamos en la ética de la justicia, porque en sus posturas universales puede anular diferencias. En cambio la ética del cuidado valora el respeto a la diversidad y al otro, y convergen sectores de la sociedad, fruto de las implicaciones negativas que lo otro quiere significar ${ }^{11}$.

Esa imparcialidad cae en evitar la otredad desde dos formas, la especificidad de las situaciones y la diferencia entre los sujetos morales ${ }^{12}$ : «yo no estoy ni en la piel ni en el contexto del otro ${ }^{13}$.

7. LOMAS, Carlos. « ¿El otoño del patriarcado? El aprendizaje de la masculinidad y de la feminidad en la cultura de masas y la igualdad entre hombres y mujeres», Cuadernos de Trabajo Social 18 (2005), pp. 259-278.

8. RIVERA, María Milagros. «La violencia contra las mujeres no es violencia de género», DUODA Revista d'EstudisFeministes 21 (2001), p. 38.

9. RiverA, María Milagros. Op. cit., p. 39.

10. LOMAS, Carlos. "¿La escuela es un infierno? Violencia escolar y construcción cultural de la masculinidad». Revista de Educación 342 (2007), p. 88.

11. Comins, Irene. «Del miedo a la diversidad a la ética del cuidado: una perspectiva de género». Convergencia Revista de Ciencias Sociales 10, 33 (2003), pp. 97-122.

12. YounG, Iris Marion. «Imparcialidad y lo cívico-público: Algunas implicaciones de las críticas feministas a la teoría moral y política». En La democracia en sus textos. Madrid, Alianza Editorial, 1998. pp. 445-470.

13. Comins, Irene. Op. cit., p. 114.

Feminismo/s 25, junio 2015, pp. 133-157 
Gilligan ${ }^{14}$ en su obra In a Different Voice, señala una concepción del mundo diferente a la patriarcal. Creó la ética del cuidado tras conocer la ética de la justicia de su profesor Kohlberg, con el objetivo de analizar una teoría moral feminista teniendo en cuenta como sujeto a las mujeres en situaciones reales. Comins ${ }^{15}$ llegó a la conclusión de que su estudio explica una distinta socialización, teniendo en cuenta la importancia de la diferencia y de la diversidad.

La ética de la justicia mueve variables universales, anulando las diferencias, en cambio la ética del cuidado valora el respeto a la diversidad y al otro: «se apoya en la premisa de la no violencia: que no se debe dañar a nadie» ${ }^{16}$.

\section{1. ¿Por qué llevar esta no-violencia al ámbito educativo?}

Saliendo de la ética del cuidado pero a la vez no alejándonos de posturas sobre la no-violencia, existen respuestas de querer sostener la violencia, a veces entendida como una justificación o protección del poder del Estado u otra orden o institución, victimizando a quienes reciben violencia. Si el conflicto se resuelve solo dialógicamente, puede actuar de forma excluyente de quienes requieren de «resistencias activas»:

Negarnos a nosotrxs mismxs las vías no-pacifistas para fortalecer el movimiento y debilitar o sabotear estas estructuras es lo mismo que quedarnos en un bote a punto de hundirse... ${ }^{17}$

Nuestros centros deberían honorar a lxs activistas militantes encarceladxs o a aquellxs asesinadxs por el Estado; nuestras escuelas libres deben enseñar la autodefensa y la historia de la lucha ${ }^{18}$.

Cuando hablamos de justificar la no-violencia, ¿cómo podemos dejar a un lado el daño causado, la pacificación sin resolver conflictos?, el:

«son cosa de niños», o «es cosa de la edad», «necesita buscar su identidad y por eso insulta», «mi hija dice que lo echen del instituto y que no vuelva» ${ }^{19}$. suelen acusar solo a mi hijo en peleas en clase, y son cosa de varios ${ }^{20}$.

14. Gilligan, Carol. In a different voice. Cambridge, Harvard University Press, 1982.

15. Comins, Irene. Op. cit.

16. Gilligan, Carol. La moral y la teoría: psicología del desarrollo femenino. México, Fondo de Cultura Económica, 1985, p. 281.

17. Gelderloos, Peter. Cómo la no violencia protege al Estado. Barcelona, Edicions Anomia, 2010, p. 108

18. GelderloOS, Peter. Op. cit., p. 158.

19. Citas tomadas de reuniones con madres y padres en la escuela.

20. Taller de mujeres magrebíes, abril 2015. 
Concretar en una reflexión sobre la conciliación es válido si la estructura del centro, del ámbito social lo permite. Pero cuando esto no es un principio para la institución educativa, se puede crear una compasión sin acción, y ¿dónde quedan las reformas?, ¿cuánto tiempo es necesario para cambios institucionales, prácticas populares o seguidoras de ideologías alejadas de la realidad?

\subsection{Descolonialismo versus despatriarcalismo}

Descolonizar es necesario desde el reconocimiento de la existencia del sistema patriarcal ${ }^{21}$ en las instituciones, en los comportamientos sociales aprendidos y en sus consecuencias. Este ejemplo está todos los días en los patios del colegio, cuando las niñas solicitan jugar al voleibol y tanto profesores ${ }^{22}$ como compañeros dicen:

¿No queréis la igualdad, pues jugar al fútbol? ${ }^{23}$.

No tenemos tiempo para tratar el problema ${ }^{24}$,

Hay que solucionarlo como sea antes de llamar a la policía ${ }^{25}$.

El control es la base de muchas soluciones, y reconocemos la importancia de descolonizar el poder del proceso por el cual, el autor Aníbal Quijano ${ }^{26}$ nos descifra desde varios enfoques en su crítica al eurocentrismo como delimitador de las estructuras sociales y estatales de poderes, y claramente reconoce que las diferencias de género están marcadas desde un patriarcado que necesita de la diferenciación sexual para un control mayor. Walter Mignolo ${ }^{27}$ señala un patriarcado que regula y determina las relaciones sociales de género y las preferencias sexuales con un mandato de autoridad en la organización socieconómica y del conocimiento, pero: ¿desde dónde observamos las relaciones de género y la violencia?

Necesitamos entender la organización de lo social para sí poder hacer visible nuestra colaboración con una violencia de género sistemáticamente

21. http://www.ipsnoticias.net/2014/06/tras-la-descolonizacion-la-despatriarcalizacion/, consultado el 01-04-2015.

22. Profesor de Educación Física de $1 .^{\circ}$ ESO, relatoría del taller de discusión de niñas.

23. Taller de discusión de niñas.

24. Jefa de estudios en un instituto en Murcia, febrero 2015.

25. Jefes de estudios de un IES en Murcia.

26. QujJAnO, Aníbal. «Colonialidad del Poder y Clasificación social». Journal of WouldSystem Research 2 (2000), pp. 342-386.

27. Mignolo, Walter (comp.). Género y Descolonialidad. Buenos Aires, Del Signo, 2008, p. 9. 
racializada para así llegar a un ineludible reconocimiento de esa colaboración en nuestros mapas de la realidad ${ }^{28}$.

\section{Etnografías que permiten conocer violencias de género}

Este estudio parte de etnografías realizadas en contextos educativos institucionales y comunitarios. Se enfatiza sobre violencias y estrategias de intervención y/o acompañamiento entre diversidades culturales y de género, personas, que puede vincularse a la noción de «poner en práctica la idea de "diferencias comunes" como base para una solidaridad más profunda» ${ }^{29}$.

A partir del modelo que aconseja Chandra Talpade ${ }^{30}$ entre pedagogas feministas: feminista como turista, feminista como exploradora y/o modelo de solidaridad feminista o de estudios comparativos feministas, nos orientamos a reconocer la solidaridad como clave para los feminismos. Esto es aplicable en el deber de reconocer desde qué prisma nos encontramos, o al menos reflexionar por qué esta caracterización puede cambiar a lo largo del proceso de investigación acción.

Como la misma autora revela:

Cada uno de estos puntos de vista se cimenta sobre maneras particulares de concebir lo global y lo local, el papel de las mujeres y el de la identidad nacional, y cada modelo académico presenta maneras e historias diferentes de cruzar fronteras y construir puentes.

Nuestra visión se vincula a la solidaridad feminista pero en la exigencia de reconocer las identidades sociales y culturales que protagonizan estos espacios educativos: escuela formal y no formal ${ }^{31}$, en Murcia (vinculación con alumnos de $1 .^{\circ}$ ESO en un Instituto, niños y niñas en un espacio intercultural municipal junto a sus madres y alumnado de estudios superiores en educación) y en Tabasco, México (jóvenes indígenas y mestizos en educación secundaria, educación primaria y educación no formal en comunidades indígenas y rurales).

28. LugONES, María. «Colonialidad y Género: Hacia un feminismo descolonial». En Walter Mignolo (comp.), Género y Descolonialidad. Buenos Aires, Del Signo, 2008, p. 54.

29. TAlPADE, Chandra. Op. cit., p. 437.

30. Ibíd., p. 437.

31. La escuela no formal también podemos denominarla comunitaria, está vinculada más hacia el desarrollo del barrio, a proyectos sociales y a suplir las necesidades que la escuela oficialista no puede cumplir. 


\subsection{Metodologías activas en reflexión}

A partir de narrativas, talleres de discusión y observación participante, se ha entretejido una compleja relación con una exposición de formas de entender y actuar sobre la violencia de género.

Realizar etnografía con niñas y niños es de gran complejidad, las entrevistas diseñadas suelen quedarse en la trastienda porque en el momento, dejan tu pregunta y se van por otras que consideran de más interés. Muchos autores confirman que la etnografía ayuda a comprender cómo las relaciones moldean los contextos sociales y emocionales de los niños, algunas de estas razones se explican a continuación ${ }^{32}$ : en primer lugar por conocer de forma más íntima los escenarios de los niños, y en segundo porque se adapta a sus necesidades temporales y su estudio desde una etnografía longitudinal y sus fundamentos de la vida cotidiana.

Consideramos más fiable las entrevistas grupales ${ }^{33}$, el proceso de recolección de información ha sido longitudinal en el tiempo, lo simbólico sobre la violencia de género cambiaba entre los grupos en función de su madurez y de con quiénes compartían este espacio de discusión.

La dificultad estaba en lo imposible de mantener la concentración entre lo que pertenecía a niños y lo que pertenecía a niñas, no era necesaria esta distinción. Esto permite abrir miras hacia la visión teórica de lo relacional, pero puede excluir en función de la no diferenciación sexual.

Para evitar esto, confiamos en la etnografía reflexiva que permite un ir y venir al escenario así como la perspectiva «reflexiva histórico-cultural», que se basa en la doble historicidad de los sujetos y los métodos como problemáticos de su investigación ${ }^{34}$.

La distinción se daba más sobre edades, generaciones, incluso entre comunidades rurales y ciudades ${ }^{35}$. Parte analizada en esta investigación era considerar la recategorización del género o de lo que denomina María Lugones «Igualitarismo Ginecrático y No-Engenerizado», al plantear que en algunas sociedades se «incluía al género como un principio de organización

32. Buchimder, Mara; Longhofer, Jeffrey; BARrett, Thomas y Lawson, Peter. «Ethnographic approaches to child care research», Journal of Early Childhood Research (2006), pp. 45-63.

33. Como también afirma Iván Rodríguez. «Redefiniendo el trabajo metodológico cualitativo con niños», EMPIRIA 12 (2006), pp. 65-88.

34. Wulf, Cristoph. «Antropología Histórico-Cultural de la Educación». Estudios Filosóficos LV (2006), p. 462.

35. En este caso se vieron ciudades en España como Tarragona, Murcia (Abanilla, Las Torres de Cotillas, Torre Pacheco y Alhama de Murcia), y en Marruecos. 
social (refiriéndose a) otro caso de «dominación Occidental»» ${ }^{36}$, claro que es inviable pensar que los participantes de la etnografía estén salvados de las categorías de género, pero abre paso a nuevas perspectivas, posiblemente más acordes a emociones y a lo transgénero ${ }^{37}$.

Incluimos la autobiografía de las autoras y sus intentos desde la experiencia a lo teórico, clave en la formación del profesorado en los Grados de Educación y en voluntariado comunitario, que se visibiliza en una pregunta continúa en los espacios creados, «¿cómo lo mejorarías?, ¿qué faltaría en la escuela, en la comunidad, en las familias para conseguir un buen vivir?», « ¿ cómo os gustaría que fueran los docentes?». A la vez invitando a una acción de aprendizaje de servicio ${ }^{38}$ y a una continua reflexión sobre qué es comunidad o colectivo para el cuidado.

\subsection{Etnografías de escenarios e identidades simbólicas con perspectiva de género}

Los escenarios educativos también han sido diversos y diferentes, comparar feminismos ha sido una apuesta para descolonizar, y en el proceso de reflexión de nuestra práctica docente y discente, corroboramos una visión antropológica del feminismo acorde a la alteridad y la solidaridad.

Las autoras e investigadoras nos hacemos ver como acompañantes. La palabra acompañante ${ }^{39}$ tiene una simbología en sí, en América Latina, en este caso en Guatemala, se utiliza para personas de origen «extranjero», es decir «no de la comunidad», la mayoría son de la comunidad internacional (europeos y norteamericanos de ONG) que servían de testigos para denuncias contra los Derechos Humanos, en este caso en países que están en periodos de conflicto o postconflicto bélico.

Actualmente acompañantes desde su simbólico es no crear intervención social o asistencialismo, en este caso, lo percibimos desde la colaboración,

36. LugONES, María. Op. cit., p. 33.

37. Este no es un espacio para profundizar sobre el concepto transgénero pero es necesario emprender lo simbólico desde este aspecto con autores como: BRAIDOTTI, Rosi. Nomadic subjects: Embodiment and sexual difference in contemporary feminist theory, Columbia University Press, 2013. Destacamos de su aportación la crítica que formula a las teorías en pro de las expresiones populares y la experiencia, determina así el nomadismo simbólico y la tolerancia desde lo singular de las identidades, donde la transgeneridad es parte de la heterogeneidad, no reducibles al binario genérico.

38. Kendall, Jane C. Combining Service and Learning. A Resource Book for Community and Public Service. Raleigh (Carolina del Norte), National Society for Internships and Experiential Education, 1990.

39. MuÑoz, Práxedes. «De la violencia surge una cultura política de resistencia -las CPR del Ixcán- que deriva en una participación estratégica de las municipalidades». Revista Pueblos y Fronteras digital 5.8 (diciembre 2009-mayo 2010), pp.196-236. 
aprehendida desde experiencias con población indígena ${ }^{40}$, en espacios comunitarios interculturales e intergeneracionales, donde todas las participantes asumimos la intervención desde el yo reflexivo y desde la otredad.

Este proceso no está ultimado ni preparado desde la objetividad, es un espacio para resituar cada realidad y no producir desde el universalismo feminista $^{41}$, y apoyar una descolonización de un feminismo dirigido que actualmente lo sometemos a reflexión, en función de los símbolos culturales y de los estereotipos que puede excluir a algunas mujeres.

A partir de este propósito del cuidado de las propias investigadoras, presentamos diversas experiencias educativas donde convergen infancia y juventud en escenarios de educación formal y no formal, con sus madres en espacios, algunos intergeneracionales ${ }^{42}$, además de espacios públicos (discursos en la calle, plazas y centros culturales) y privados (casas con estancias individuales). Es inevitable que tengamos presentes identidades culturales y más al participar en escenarios de población indígena y mestiza en México y en España entre culturas migrantes y «españolas». Ambas realidades son complejas y permean entre estereotipos y desconocimiento y/o desinterés de procesos interculturales, solo en un reconocimiento multicultural pero no apasionado de descolonizar los saberes ${ }^{43}$.

A continuación se destacan algunos símbolos que consideramos importantes de reflexionar y de trabajar desde las escuelas, familias y comunidad de una forma urgente pero también interdisciplinar, a partir de un currículum oculto de por vida, que sea incluyente desde lo local a lo global y desde la escuela a la comunidad y viceversa ${ }^{44}$.

40. LeYVA, Xochitl; SPEED, Shannon. «Hacia la investigación descolonizada: nuestra experiencia de co-labor». Gobernar (en) la diversidad: experiencias indígenas desde América Latina. Hacia la investigación de colabor, 2008, pp. 34-59.

41. SuÁREZ, Liliana y HERnÁNDEZ, Rosalva Aída. Op. cit.

42. Estos han sido en un espacio intercultural entre mujeres de origen magrebí y sus hijas y en México en Tabasco (Tapotzingo, la Barra de San Pedro, Villahermosa).

43. Podríamos hacer una categoría entre autóctono y extranjero, pero huyendo de estereotipos, vemos conveniente la dimensión comunidad y escuela porque facilita la visión de necesidades de descolonizar espacios dirigidos o semidirigidos frente a la propia identidad de los participantes.

44. También posibles entre lo público y privado, pero somos conscientes de que lo público se crea en espacios también privados enmarcados en procesos identitarios. La falta de educación comunitaria se aleja de la escuela reglada o educación formal por la poca participación sobre la ciudadanía activa de las aulas. 
3.2.1. Etnografía reflexiva desde espacios educativos reglados: ¿La escuela como institución ayuda en el proceso de igualdad entre niños y niñas?

A partir de una etnografía colaborativa y activa, se pretende una escucha y visibilizar no solo lo que hace más ruido, sino lo que hace presente la alteridad.

La violencia se siente más en los últimos cursos de primaria, se acentúa en cuanto al cambio físico de niña a joven, cuando se complican los procesos propios de identidad y de pertenencia. Es mucha la violencia que se perpetúa a chicas, por ejemplo:

«ieres peluda, quítate esos pelos!, o ¡estás plana!...», (y de forma un tanto defensiva y quienes son más atrevidas, les contestan): «¿tienes una tableta de chocolate (ríen)? $»^{45}$.

Es imprescindible también el número de niños o niñas que están en una clase o en un grupo de amigos, pero recordemos que la violencia para la minoría es importante y debe de estar acorde con la justicia social. Si el grupo de clase quiere jugar al futbol pero las chicas y un niño prefieren jugar al «mate», se deja a la mayoría que decida porque en muchas ocasiones suelen boicotear el juego.

Algo que consideran un problema es la bipolaridad, "ahora te insulto y ahora eres mi amiga». Consideran falta de personalidad, y acentúan el sentido de «incomprensión» en edades complicadas, la búsqueda de identidades refuerza el tener que comportarse como hacen líderes de grupos, «si ellos insultan yo también» pero buscan aliados para insultar a otros.

También son usuales los insultos por falta de saber comunicarse, «no sé por qué lo hacen, me dicen puta», en este caso a chicas y «maricón» a chicos, ¿suele ser cuando tienen relaciones más libres en cuanto a los estereotipos marcados en el escenario donde se encuentran?, es decir, chicas que se relacionan con chicos y chicos que se relacionan con chicas, o como dicen ellas, «es una forma de llamar la atención a la que le gusta», «insultan porque se creen guay», «piensan solo en hacerte daño $»^{46}$.

Si hablamos del medio virtual, la violencia se va acentuando, antes eran cartas y ahora son múltiples los espacios (chat, whatsApp, Instagram, entre otros), son conscientes de que están ahí y dicen:

45. Grupo de discusión marzo 2015.

46. Grupo de discusión marzo 2015. 
«tenemos que aprender a utilizarlo», "probamos para ver qué pasa», «es más fácil hablar desde ahí» y «es algo personal, no es de la escuela, el maestro no debe meterse».

En cuanto a la experiencia que tienen sobre las relaciones «amorosas» a partir de los 12, se van estableciendo desde un ámbito virtual, incontrolable por la sociedad y familias ${ }^{47}$.

Es muy significativo el dato que nos aporta el Informe sobre «La percepción de la violencia de género en la adolescencia y la juventud», elaborado por Verónica de Miguel Luken, para la Secretaría de Estado de Servicios Sociales e Igualdad ${ }^{48}$, el grado de «tolerancia hacia la violencia de género», que existe entre jóvenes de 15 y 29 años, es necesario de abarcar a nivel teórico, ya que existen experiencias dentro del ámbito educativo, que ponen de manifiesto que los «celos» están muy presentes o que como podemos ver en el mismo informe, el 33 \% de las chicas y chicos, considera que es «aceptable en ocasiones» o « inevitable» que en una pareja tengan lugar prácticas como controlar los horarios del otro, lo que sin duda es una violencia por control y es responsabilidad de los espacios educativos que deba ser trabajado.

Manifiestan que en los pueblos no ocurre esto, el ritmo es diferente, se perciben velocidades de crecimiento, ganas de hacerse mayores pero no necesitan insultarse para darse a conocer o llamar la atención, hay un trato más vinculado a la comunidad:

en Abanilla era distinto, nos llevábamos todos bien, la gente es maja, y cuando salimos al centro vamos todos juntos, no había ningún insulto.

Sobre las acciones en cuanto a violencia, ¿el centro educativo qué hace ${ }^{49}$ :

(...) «en este caso lo normal es que quede en el olvido, a veces que se pidan perdón, el jefe de estudios se tira contigo hasta 4 horas de clase perdiendo el tiempo, hay que esperar que él pueda y entonces te dice lo mismo repetidamente, 5 veces me dijo lo mismo, pero ya está. Solo si es grave te expulsan pero eso no es un castigo, es guay», «lo que suelen hacer es castigar a toda la clase, los tutores dicen que es responsabilidad de todos el mal desarrollo de la clase», «lo más grave que ocurre son las agresiones morales y físicas de todos

47. Discusión de madres y padres en reuniones del ISE, curso 2014/2015. Tema difícil de conseguir información en los talleres de niñas y niños.

48. Delegación del Gobierno para la Violencia de Género. Informe sobre la Percepción de la violencia de género en la adolescencia y la juventud <http://www.msssi.gob.es/ssi/violenciaGenero/publicaciones/estudiosinvestigaciones/ PDFS/Percepcion_Social__VG_Adolesc_Juv.pdf> Op. cit. consultado el 15-03-2015.

49. Pregunta que se les hacía en las entrevistas y talleres. Y diversas respuestas en clave de un lenguaje coloquial. En el grupo de discusión eran 5 jóvenes, y 3 de ellos pasaron por jefatura de estudios por un conflicto de violencia entre chicas, marzo 2015. 
los días, cuando te tiran el bocadillo, una tiza o el estuche, y se repite muchas veces», "cuando pasas del que te molesta, se acaba el problema».

En los grupos de discusión se percibe una necesidad de valorar que todos somos iguales y que todos deberíamos respetarnos. No sienten diferencias con población de origen extranjero, en cambio recuerdan que un niño de origen marroquí le dijo a una niña de origen senegalés que se iba a Londres a ver a su hermana: «ite vas en patera?», y los compañeros en la entrevista dijeron: «si hubiera sido un niño, no se atrevería a decírselo».

A continuación se especifican consideraciones sobre el grupo de discusión con niñas de origen magrebí.

En cuanto a la palabra «mora», actualmente tiene muchos símbolos, de ser una palabra para hacer burla, se ha convertido en una identidad «a mí ya me da igual, estoy orgullosa de ser mora $^{50}{ }$, en cambio otra chica decía que a ella le parecía esta palabra un insulto cuando iba a los primeros cursos de primaria pero que tras pasar a $4 .^{\circ}$, ya no le importaba. Ella considera que cuando ya era más mayor, en $5 .^{\circ}$ y $6 .^{\circ}$, ya no le insultaban, «me hice de respetar»:

Una niña árabe explica cómo siente la violencia:

La violencia eran apodos, se metían hasta con mis zapatos, de todo, en España siempre me insultan, en Marruecos es diferente, te sientes mejor, puedes ir a donde quieras sin pensar que te van a insultar o a decir algo (...) mi sueño es ser maestra. Aquí no lo quiero ser porque seguro que no me toman en serio, seguro que dirán que soy árabe que no valgo. Por eso lo quiero ser en Marruecos. También quiero tener un hospital mío en el que cure a toda la gente que no tenga dinero para curarse $e^{51}$.

Esta niña, antes de afirmar lo que quería ser, expresó que para ella violencia era cómo trataban los empleados médicos en España a enfermos de origen extranjero, porque ha observado muchas veces una agresividad por ser de fuera.

En el grupo de discusión, las tres chicas coincidían en preferir trabajar con chicas que con chicos. Y se prestaron a decir que cuando eran débiles y mostraban dolor o llanto, era peor porque el insulto no cesaba, al contrario, aumentaba.

Sobre el velo que llevan niñas y chicas musulmanas, reconocen que es un símbolo de protección frente al hombre y no de machismo, aquí se percibe una manifestación contra la violencia de género. Interesante de reflexionar

50. Testimonio de Fátima, 2. ${ }^{\circ}$ ESO 16 años. Localidad Alhama de Murcia, marzo 2015.

51. Entrevista a una niña de origen marroquí que vive en un pueblo de Murcia, se siente marroquí, tiene casi 13 años, marzo 2015. 
desde el movimiento feminista islámico y el propio de las mujeres protagonistas de estos talleres.

Cuando existen noticias sobre terrorismo islámico, se ha manifestado violencia de género de forma rápida y simbólica con carteles donde ponían una foto de una mujer con velo y una frase «no queremos terroristas $»^{52}$. En cuanto al velo decían: «si te pones pañuelo también te insultan, 'si es que no tienes pelo, si es que eres fea', los chicos más insultan que las chicas por llevar pañuelo».

El respeto parece ser clave en este proceso, prefieren que sus hijas lleven el velo, confían en ello pero también ven a jóvenes que no quieren ponérselo y no se consideran alejadas del Islam. Algo a profundizar en otro espacio. Por ahora no sienten violencia contra el velo por parte de las instituciones escolares en Murcia. En cambio madres confirman que conocen casos de quitarle el pañuelo a su hija, dejando a la niña árabe llorando:

para mí que es culpa de los maestros, no falta eso de decirle moro y marrano, le quitan el pañuelo a mi hija, ella queda llorando y el profesor no hace nada $a^{53}$.

\subsubsection{Etnografía reflexiva desde espacios educativos comunitarios ${ }^{54}$}

En este apartado presentamos intereses comunitarios desde población indígena y mestiza en México y población magrebí en España. Ambas realidades encuentran en la comunidad un aliento de pertenencia, pero todavía queda mucho por hacer en la inclusión del indígena en la población mestiza y del extranjero inmigrante en su sociedad receptora.

El concepto de comunidad en América Latina se escapa de nuestro proceso actual en España o Europa. El sentido de educación está íntimamente ligado a lo que ocurre en la comunidad, la alfabetización, la ayuda del Estado, la seguridad, el devenir de líderes, las mujeres cuidadoras, la violencia, etc.

Para despertar a la conciencia de cómo el investigador se mueve en un saber simbólico, a veces de índole segregador, se requiere analizar las necesidades básicas de las comunidades, circunscritas a escenarios únicos, con procesos propios e irrepetibles y singulares, ante la amenaza de

52. Testimonio de Fátima en un IES de Alhama de Murcia, abril 2015.

53. Grupo de discusión con madres magrebíes, abril 2015.

54. Investigación etnográfica sobre identidades que convergen en Tabasco: población indígena, pastoral Social Indígena Iknaskinjha, la Red Municipalista, Mujeres Productivas Asociadas de Cunduacán, Movimiento Pro Derechos Humanos y el Instituto Tecnológico Bilingüe en Tabasco. Y en España el espacio intercultural creado por la Asociación de Mujeres por África, AMÁFRICA. 
fomentar la generalización en las clasificaciones que favorecen la creación de fronteras, algo incomprensible e incoherente en la educación y prácticas interculturales ${ }^{55}$.

Como ejemplos sobre violencia es clave la violencia institucional y/o institucionalizada, en aspectos de la propia comunidad y de estructuras de poder que se van consolidando incluso en las organizaciones comunitarias y sociales. El colonialismo en las comunidades indígenas en América, el caso de México, está latente y mantiene toda una estructura violenta en cuanto al racismo, el capitalismo y el patriarcado ${ }^{56}$.

Pero para analizar esta diferencia de género es necesario entender cómo es la mujer y el hombre indígena ${ }^{57}$ : maya, yokot'an, y otras; la mujer y el hombre de origen inmigrante de diferentes países: Marruecos, Argelia y Senegal; las familias mixtas; y sin perder de vista, las diferentes generaciones que incluyen y varían sus propias identidades.

Nos puede ayudar la caracterización que se ha hecho de la fortaleza de la malinche, mujer de carga simbólica como mestiza que apoyó a Hernán Cortés en la colonización de México, y a la vez en intentar entenderse entre vencedores y vencidos ${ }^{58}$. No es la malinche quien nos puede mostrar cómo es la mujer en este caso, maya y tabasqueña, pero es otra forma de ver qué violencia y en qué historia se va perpetuando una violencia de la que han sido fruto las mujeres en América, entrabada en un desalojo de tierras cuando conviene y someterlas a esclavitud. Actualmente sigue en la memoria colectiva como la principal violencia que se escucha en las comunidades indígenas en resistencia activa, actualmente en la región estudiada, por las explotaciones petroleras sufridas desde la mitad del S. XX hasta la actualidad.

Estos procesos activos sí están directamente relacionados con la violencia de género en las políticas municipales en busca de estrategias defensivas de los derechos de las mujeres, como sigue siendo la Red Municipalista

55. MuÑOZ, Práxedes. «Investigaciones experienciales, una apuesta para descubrir la interculturalidad desde la educación política y la simbología comunitaria». En Angélica Mendieta Ramírez y Clara Janneth Santos (coord.), Líneas emergentes en la investigación de vanguardia. Madrid, McGraw-Hill, 2014, pp. 10-11, 449-459.

56. MAMẢ MAQUIN - IXMUCANÉ - MADRE TIERRA, Escuela nacional de formación política integral alianza de mujeres rurales por la vida, tierra y dignidad, 2006.

57. MuÑOZ, Práxedes. «Experiencias de construcción de resistencias e identidades de género». En Luis Rodrigo, Sergio E. Hernández y María del Carmen Ventura (coords.), Democracia, cultura política y ciudadanía en el México de hoy. México, UNAM, 2014, pp.175-197.

58. Cocimano, Gabriel. «Malinche, Borges y la fascinación por lo foráneo en la cultura latinoamericana. Entre dos mundos».American@ 3, 2 (2005), pp. 39-54. 
de Tabasco ${ }^{59}$. En este caso el proceso intergeneracional está activo, se puede confiar en una comunicación reflexiva sobre qué es óptimo o no en una educación, se escucha a los mayores, se respetan sus pensamientos, pero a la vez se conservan unos prejuicios en cuanto al ser indígena, que subyace en un racismo colonialista, en la academia y en las asociaciones pro derechos humanos, esta última en relación a una colonización del concepto de desarrollo.

El significado de la paridad está latente en la población indígena movilizada, activa y no en el resto de organizaciones de mujeres. Pero cada vez es más real entre mujeres indígenas y mestizas así como entre mujeres del campo y de la urbe, en una expansión del feminismo solidario. Un ejemplo de interés es cómo en el Centro Tecnológico Bilingüe, jóvenes mestizos querían estudiar el idioma yokot'an porque eran conscientes de la importancia de recuperar y comprender la cultura de las poblaciones indígenas de su propio Estado. Así nació un proceso de revalorización desde el trabajo comunitario de la Pastoral social indígena de Tabasco, Iknaskhinjha ${ }^{60}$, que ha revertido en la demanda y desarrollo del primer centro bilingüe, castellano y yokot'an, en Tabasco, México.

El carácter de la mujer yokot'an es fuerte, libre y actúa por ideales. Reconoce perfectamente las relaciones machistas en la escuela y en la comunidad, y hay comunidades activas donde las jóvenes heredan el compromiso político contra la colonialidad gubernamental: «Han sido muchos años de colonia, ya sabemos cómo resistir ${ }^{61} »$.

Hay grandes diferencias en comunidades de población indígena de la mestiza, los comportamientos son casi opuestos, así como las comunidades en la costa de las que están al interior. Del trabajo etnográfico en los centros educativos y en los colectivos, destacamos el sentido de la comunidad, los estereotipos se conservan pero existe pertenencia a un lugar, a un grupo, y sentimientos contra la segregación y los gobiernos autócratas que reconocen desde su propia historia colonial.

En las escuelas se percibe una idea de patria, del cuidado de la comunidad, de su desarrollo, y tanto en secundaria como en primaria, las relaciones de género son respetuosas y reconocen valores intergeneracionales.

59. MuÑoz, Práxedes. Op. cit.

60. MuÑOZ, Práxedes. «Desde el análisis de la realidad y la lucha por los derechos humanos a seguir nuestros corazones». Consejo indígena Ik'naskinjha I Congreso Nacional de Antropología Social y Etnología (2010).

61. Testimonio de la presidenta de la Asociación de mujeres de Tamulté de la Sabana, Tabasco. Entrevista 2011. 
Otras experiencias comunitarias como el espacio alternativo existente en un centro cultural municipal (intercultural e intergeneracional) con mujeres e hijas de origen magrebíe y mujeres españolas, se han reconocido muestras de violencia de género, enclavadas en hegemonías contra la interculturalidad. Es el caso de las demandas de clase de árabe en su municipio de Murcia. Para las mujeres es importante que sus hijos aprendan árabe y en una práctica en un espacio público, el centro cultural, fue designado como peligroso, y se prohibió cualquier actividad que tuviese que ver con árabe; ellas perciben esta violencia como racismo:

en Marruecos tenemos una clase con españoles que tienen su propio colegio y aquí les dicen al Imán que se vaya, en el colegio no quieren aprender religión suya (católica) pero nosotros sí queremos aprender árabe.

En este espacio se ha observado la necesidad de hacer un trabajo colaborativo, para mostrar sus identidades y así, ser respetadas por la comunidad «de recepción», actualmente está en procesos de discusión pero de un deseo, «hay niños que no respetan que sus compañeras lleven velo, si lo explicamos podrán entendernos» ${ }^{62}$.

En diferentes escenarios se percibe que en lo público las niñas son cuidadoras de sus hermanos pequeños, y los chicos son cuidadores cuando no tienen hermanas, la violencia de género se observa más en aspectos de relaciones de noviazgo y celos, pero en los trabajos escolares, existe un vínculo de igualdad interesante y con un enfoque femenino en cuanto a estrategias de resistencias colectivas ${ }^{63}$.

\section{Cómo se actúa sobre esta violencia de género: «¿queda tiempo para esto?»}

La violencia en la cultura escolar no puede entenderse sin parámetros como la convivencia, la construcción de masculinidades y las relaciones afectivas sexuales $^{64}$, además de nuestras propias construcciones de las relaciones de género en el ámbito socioeducativo y el privado o familiar, a veces difícil de separar.

62. Grupo de discusión, abril 2015.

63. Éstas se perciben en México en la personalidad de alcaldes y alcaldesas locales, líderes comunitarios y maestros y maestras, interesante de analizar desde una transgénero que rebasa fronteras biológicas y que en ciertas culturas se percibe claramente desde la ética del cuidado y un activismo feminizado.

64. Rodríguez, Carmen. Género y cultura escolar. Madrid, Ediciones Morata, 2011. 
Comenzar por investigar cuánto y cómo se subvencionan programas contra la violencia de género nos pone en la realidad de un abismo inconmensurable. Aunque se relaten muchos informes de prevención, sensibilización entre otros o como dice el primer párrafo del apartado I sobre la Exposición de Motivos de la Ley Integral, que dice así: «se manifiesta como el símbolo más brutal de la desigualdad existente en nuestra sociedad ${ }^{65}$.

La autora Carmen Rodríguez ${ }^{66}$ afirma que la mayoría de programas sobre la lucha contra la violencia en la escuela, deja de lado la identidad sexual. Se siguen teniendo en cuenta que los comportamientos más violentos o que no resuelven conflictos, suelen ser características de niños o chicos. Carlos Lomas $^{67}$ (2007) nos recuerda ciertas violencias, femeninas y masculinas: una violencia masculina más fuerte y externa, frente a una violencia femenina que es silenciosa y oculta. Collell y Escudé ${ }^{68}$ clasifican la violencia escolar en maltrato físico, verbal y relacional. Trianes ${ }^{69}$ reconoce seis factores que favorecen actitudes del conflicto en escenarios escolares: personales, familiares, contextuales, ambientales, relacionales e institucionales. Ante estas clasificaciones, reconocer los tipos de violencia, qué no es violencia o cuál es el límite que sí permite esta violación a la persona, está por delimitarse y es cambiante en cada realidad social.

Así mismo sus protagonistas advierten desde sus símbolos e identidades:

«podemos madurar», «nos cuidamos entre nosotros, no es entre niños o niñas, sino porque somos amigos», «no hacer problema, no necesitamos que nos cuiden los mayores, no lo entendéis», "no castigarnos a todos por igual porque no somos iguales», «la escuela no nos deja desarrollarnos, aprender árabe es un derecho», «dejar que enseñe cómo es mi cultura, ¿por qué solo les interesa la henna? ${ }^{70} »$.

En los grupos de discusión, jóvenes relataron que la violencia es física y moral o psicológica, pero la estructural la entienden en la invisibilidad de las estructuras educativas, tanto de necesidades como de pertenencias e identidades,

65. Ley Orgánica 1/2004, de 28 de diciembre, de Medidas de Protección Integral contra la Violencia de Género. Párrafo 21760: La violencia de género se enfoca por la Ley de un modo integral y multidisciplinar, empezando por el proceso de socialización y educación, p. 2.

66. RodríGueZ, Carmen. Op. cit., p. 89.

67. LOMAS, Carlos. Op. cit., 2007, p. 97.

68. Collell, Jordi; ESCUDÉ, Carme. «La violència entre iguals a l'escola: el Bullying», Àmbits de psicopedagogía 4 (2002), pp. 20-24.

69. TRIANES, María Victoria. La violencia en contextos escolares. Málaga, Aljibe, 2000.

70. Relatorías de las entrevistas y grupos de discusión, marzo 2015.

Feminismo/s 25, junio 2015, pp. 133-157 
todo por igual sin dar pie a los múltiples saberes sobre violencia, género y actuaciones de mejora.

\subsection{Práctica presente en el aula}

A pesar de lo expresado anteriormente, hay buenas prácticas que permiten trabajar estos aspectos en espacios educativos. Así como el Proyecto Relaciona $^{71}$, desde el ámbito de la escuela y el objetivo de las relaciones, reconoce las siguientes manifestaciones de violencia, incluyendo la necesidad de enfrentar los significados a lo genérico: a. en el uso del lenguaje que no nombra a las mujeres y que las infravalora; b. en un lenguaje que usa expresiones referidas al sexo femenino para insultar; c. en una educación que limita los significados de lo masculino y lo femenino y; d. en el uso de libros que reproducen estereotipos sexistas y que no recogen las aportaciones de las mujeres a la sociedad y a la cultura.

Otras experiencias educativas que ponemos en conocimiento del alumnado universitario ${ }^{72}$, para su conocimiento pedagógico-didáctico y como herramienta en la sensibilización y la lucha contra la violencia de género son por ejemplo: el Programa La Máscara del Amor, que desde el curso 2010-2011 se ha puesto a través de un taller literario y cinematográfico en la Comunidad Autónoma de la Región de Murcia, para la prevención de la violencia en la pareja entre la población juvenil. Animando a la lectura de la novela de Pascual Alapont, titulada El infierno de Marta; o el proyecto europeo Gender is Primary. Approaching non-violent conflict resolution from a gender perspective ${ }^{73}$.

También está el colectivo de mujeres magrebíes y senegalesas, en el centro cívico de su barrio y el espacio intercultural en proceso de desarrollo comunitario emancipatorio a partir de sus propios procesos socioculturales, eliminando la asistencia. Y por último el proceso etnográfico con niñas y niños en pro de crear un espacio de reflexión y crecimiento personal en su búsqueda de oficializarse para su regularidad y disfrute madurativo a modo de talleres colaborativos de preadolescentes.

71. Serrato, Gloria Isabel; Cerviño, M. ${ }^{a}$ Jesús y HernÁndeZ Graciela. «Formación en Relación». Cuadernos de educación no sexista 24 (2008), pp. 19-30.

72. Grados de Educación Infantil, Primaria y en el Máster de Formación del Profesorado de la UCAM.

73. Se desarrolla en la Comunidad Autónoma de la Región de Murcia en colaboración con el CEIP Ntra. Sra. del Paso (La Nora, Murcia) donde nuestro alumnado realiza su Practicum, y la Asociación contra la Violencia Doméstica de la Región de Murcia (AVIDA), con la Consejería de Educación, Cultura y Universidades, en los niveles de $2 .^{\circ}$ y $3 .^{\circ}$ de primaria. 


\section{Conclusiones}

El cambio civilizatorio y la cultura en los que estamos inmersos son tan radicales que no nos permiten tomar conciencia plena de los profundos cambios que conllevan. Asistimos por primera vez en la historia de la evolución humana a la confluencia de tres aspectos que, como afirma Isabel La Moneda ${ }^{74}$, pueden ser vitales para el futuro de la humanidad, las crisis de las grandes religiones y sistemas filosóficos, la unión entre ciencia y espiritualidad, así como la mediática interconexión en tiempo real de la mayor parte del planeta. Nos hacen ver que estamos asistiendo a un cambio profundo, que conlleva la emergencia de símbolos para la persona y por ende a la sociedad que afectan al sistema educativo y a la escuela.

Por otro lado, es muy significativo que el 55\% de la población adolescente y joven afirma haber oído hablar de la Ley Integral contra la Violencia, y sin embargo el 51,9\% de la población masculina y el 48,1\% en la femenina, en edades comprendidas entre 15 a 29 años, según el nombrado Informe sobre la Percepción de la violencia de género en la adolescencia y la juventud ${ }^{75}$, no recuerde ninguna campaña gubernamental, dejando una clara significación de la lacra social a la que no terminamos de encontrar su raíz para exterminarla, o como confirmaba una jefa de estudios del instituto sobre violencia de género: «no tenemos tiempo».

Tal vez la complejidad en la diversidad de saberes y la necesidad de descolonizar conceptos que se han creído como estáticos y únicos, no permite el posicionamiento real desde la diferencia en igualdad de los derechos de las mujeres.

Abogamos por la diferencia que interactúa en el entorno compartido, desde el ámbito sociocultural, económico, político, religioso y educativo de nuestra sociedad, donde la educación influye, no siempre con la fuerza con la que creemos debe hacerse, ya que puede crear expectativas que no se corresponden con la realidad, por cuestiones de tiempo, espacios, dedicación, etc., dejándose el tema a momentos puntuales, a días internacionales y otros eventos «publicitarios». Es una vez más la invisibilidad del mundo en femenino.

Tan importante es el pensar el futuro como ayudar a crearlo, y en esta línea hemos de seguir ayudando a este mundo femenino, en su identificación,

74. Isabel la Moneda, Diego. Yo soy Tú. Propuesta para una Nueva Sociedad. Barcelona, Octaedro, 2014.

75. Delegación del Gobierno para la Violencia de Género. Informe sobre la Percepción de la violencia de género en la adolescencia y la juventud

<http://www.msssi.gob.es/ssi/violenciaGenero/publicaciones/estudiosinvestigaciones/ PDFS/Percepcion_Social_VG__Adolesc_Juv.pdf> Op. cit. consultado el 15-03-2015 
su autopercepción, en la toma de conciencia de su identidad individual y colectiva, ya que como afirma Eagleman ${ }^{76}$ : «los sectores sociales que se sienten orgullosos y cómodos con su patrimonio cultural, son mentalmente más estables». Por tanto el reto es ayudar a descubrir el patrimonio femenino, a enriquecerlo y a formar parte de él, de una forma plena.

Para ello elegimos un enfoque integrador, en el que superemos la educación tecnócrata, optando por un enfoque humanista desde el autoconocimiento y la valoración personal, que supone por ejemplo, una interioridad que pone la atención plena en la toma de conciencia del ser, en el que toda persona es diferente, pero igual en la cosmovisión holística de la espiritualidad compartida que creemos puede ayudar a dar un paso más en el ser y en la comunidad con perspectiva femenina.

También es necesario para todos los integrantes de la sociedad adquirir una pertenencia a la comunidad desde el interés del colectivo, que proporciona aberturas, no segmentos inconexos, como se observa en valores perdidos que vuelven a revalorizarse en momentos de crisis, visibles desde las familias de inmigrantes que crean sus redes de ayuda en el país receptor, y cómo van integrándose en un estado que consciente y/o inconsciente, sigue colonizando espacios socioeducativos.

Las comunidades culturales surgen del principio de la identidad de resistencia, como fuente de identidad al separarse de las sociedades civiles y las instituciones estatales a partir de las cuales se originaron, Castells ${ }^{77}$ las describe como «fronteras cerradas para proporcionar refugio (...), que borra los proyectos individuales». Y es interesante el paso o transformación a la identidad de proyecto, que como aporta Giddens ${ }^{78}$, puede llevar una negociación y a veces una transformación de los tipos de vida. Esto sería el significado de la integración, pero que suele caer en el poscolonialismo, donde vuelven a aparecer estructuras patriarcales del Estado que acoge a poblaciones más vulnerables y las «obliga» a «adaptarse o morir».

Ante esto defendemos la construcción de sujetos desde la propia resistencia. Pero cualquier enseñanza desde un compromiso de cambio y desarrollo comunitario cambia la perspectiva de las investigadoras, de los escenarios y de quienes escuchan los saberes, para crear un movimiento sinérgico que fomente la reflexión compleja y reconstituya una ética pro derechos humanos,

76. EAGLEAMAN, David. Incógnito. Anagrama, Barcelona, 2013.

77. CASTELLS, Manuel. La nueva era de la información. Economía, sociedad y cultura. V.II. Madrid, Alianza Editorial, 1998, p. 90.

78. GidDENS, Anthony. Modernity and Self-identity: Self and Society in the late Modern Age. Cambridge, Polity Press, 1991. 
no universal pero si inclusiva desde lo singular, para no asimilar una única relación educativa.

\section{Referencias bibliográficas}

BRAIDOTTI, Rosi. Nomadic subjects: Embodiment and sexual difference in contemporary feminist theory. Columbia University Press, 2013.

Buchbinder, Mara; Longhofer, Jeffrey; BARrett, Thomas y LAWson, Peter. «Ethnographic approaches to child care research». Journal of early child hood research (2006), pp. 45-63.

CASTElls, Manuel. La nueva era de la información. Economía, sociedad y cultura. V.II. Madrid, Alianza, 1998.

Cocimano, Gabriel. «Malinche, Borges y la fascinación por lo foráneo en la cultura latinoamericana. Entre dos mundos», American@ 3, 2 (2005), pp. 39-54.

COLLELL, Jordi; ESCUDÉ, Carme. «La violència entre iguals a l'escola: el Bullying». Àmbits de psicopedagogía 4 (2002), pp. 20-24.

Comins, Irene. «Del miedo a la diversidad a la ética del cuidado: una perspectiva de género». Convergencia Revista de Ciencias Sociales 10, 33 (2003), pp. 97-122.

DA MatTA, Roberto. Carnavales, malandros y héroes. Fondo de Cultura Económica, México, 2002.

DIETZ, Gunther. «Reflexividad y diálogo en etnografía colaborativa: el acompañamiento etnográfico de una institución educativa intercultural mexicana». Revista de Antropología Social 21 (2012), pp. 63-91.

EAgLeaman, David. Incógnito. Barcelona, Anagrama, 2013.

GElderloos, Peter. Cómo la no violencia protege al Estado. Barcelona, Edicions Anomia, 2010.

GIDDENS, Anthony. Modernity and Self-identity: Self and Society in the late Modern Age. Cambridge, Polity Press, 1991.

GILligan, Carol. In a different voice. Harvard University Press, 1982.

Gilligan, Carol. La moral y la teoría: psicología del desarrollo femenino. México, Fondo de Cultura Económica, 1985.

HERNÁNDEZ C, Rosalva. «Feminismos poscoloniales: Reflexiones desde el sur del río Bravo». En Liliana Suárez y Aída Hernández (coord.): Descolonizando el feminismo. Teorías y prácticas desde los márgenes 2008, pp. 75-113.

Isabel la Moneda, Diego. Yo soy Tú. Propuesta para una Nueva Sociedad. Barcelona, Octaedro, 2014.

Kendall, Jane C. Combining Service and Learning. A Resource Book for Community and Public Service. Raleigh (Carolina del Norte), National Society for Internships and Experiential Education, 1990. 
LEYvA, Xochitl; SPEED, Shannon. «Hacia la investigación descolonizada: nuestra experiencia de co-labor». En Xochitl Leyva, Araceli Burguete y Shannon Speed (coords.), Gobernar (en) la diversidad: experiencias indígenas desde América Latina. Hacia la investigación de colabor. México, CIESAS, 2008, pp. 34-59.

LOMAS, Carlos. « ¿El otoño del patriarcado? El aprendizaje de la masculinidad y de la feminidad en la cultura de masas y la igualdad entre hombres y mujeres», Cuadernos de Trabajo Social 18 (2005), pp. 259-278.

LOMAS, Carlos. "¿La escuela es un infierno?: violencia escolar y construcción cultural de la masculinidad», Revista de educación 342 (2007), pp. 83-102.

LugOnES, María. «Colonialidad y Género: Hacia un feminismo descolonial». En Walter Mignolo (comp.), Género y Descolonialidad. Buenos Aires, Del Signo, 2008, pp. 13-54.

MAMÁ MAQUIN - IXMUCANÉ - MADRE TIERRA, Escuela nacional de formación política integral alianza de mujeres rurales por la vida, tierra y dignidad (2006).

Melloni, Xavier. Hacia un tiempo de síntesis. Barcelona, Fragmenta, 2011.

Mignolo, Walter (comp.) Género y Descolonialidad. Buenos Aires, Del Signo. 2008.

Ministerio de Sanidad, Servicios Sociales e Igualdad, Percepción de la violencia de género en la adolescencia y la juventud, Madrid, Universidad de Málaga en: http://www.msssi.gob.es/ssi/violenciaGenero/publicaciones/estudiosinvestigaciones/PDFS/Percepcion__Social__VG_Adolesc_Juv.pdf

MuÑOz, Práxedes. «De la violencia surge una cultura política de resistencia -las CPR del Ixcán- que deriva en una participación estratégica de las municipalidades». Revista Pueblos y Fronteras digital 5 (2009), pp.196-236.

MuÑoz, Práxedes. Desde el análisis de la realidad y la lucha por los derechos humanos a seguir nuestros corazones. Consejo indígena Ik'naskinjha I Congreso Nacional de Antropología Social y Etnología (2010).

MuÑOZ, Práxedes: «Experiencias de construcción de resistencias e identidades de género en colectivos de mujeres en Tabasco. Dilemas de la antropología comprometida. ¿Cambios posibles?». En Luis Rodríguez, Sergio E. Hernández y María del Carmen Ventura (coords.), Democracia, cultura política y ciudadanía en el México de hoy. México, UNAM, 2014, pp. 175-197.

MuÑOZ, Práxedes. «Investigaciones experienciales, una apuesta para descubrir la interculturalidad desde la educación política y la simbología comunitaria». En Angélica Mendieta Ramírez y Clara Janneth Santos (coords.), Líneas emergentes en la investigación de vanguardia. Madrid, McGraw-Hill, 2014, pp. 449-459.

QuijAnO, Aníbal. «Colonialidad del Poder y Clasificación social». Journal of Would-System Research 2 (2000), pp. 342-386. 
RiverA, María Milagros. «La violencia contra las mujeres no es violencia de género», DUODA Revista d'Estudis Feministes 21 (2001) pp. 37-44.

RODRÍGUEZ Iván. «Redefiniendo el trabajo metodológico cualitativo con niños», Empiria 12, (2006), pp. 65-88.

Rodríguez, Carmen. Género y cultura escolar. Madrid, Ediciones Morata, 2011.

SERrato, Gloria Isabel; Cerviño, M. ${ }^{a}$ Jesús y HernándeZ, Graciela. «Formación en Relación». Cuadernos de educación no sexista 24 (2008), pp. 19-30.

TALPADE. Chandra. «Bajo los ojos de occidente. La solidaridad feminista a través de las luchas anticapitalistas». En Liliana Suárez y Aída Hernández, Descolonizando el feminismo. Teoría y prácticas desde los márgenes. Madrid, Ediciones Cátedra 2008, pp. 435-448.

TRIAnES, María Victoria. La violencia en contextos escolares. Málaga, Aljibe, 2000.

Wulf, Cristoph. «Antropología Histórico-Cultural de la Educación». Estudios Filosófico LV (2006), pp. 449-465.

YOUNG, Iris Marion. «Imparcialidad y lo cívico-público: Algunas implicaciones de las críticas feministas a la teoría moral y política». En Rafael del Águila y Fernando Vallespín, La democracia en sus textos. Madrid, Alianza, 1998, pp. 445-470. 